ORIGINAL ARTICLE

\title{
Primary or Secondary Decompressive Craniectomy: Different Indication and Outcome
}

\author{
Ahmed Al-Jishi, Rajeet Singh Saluja, Hosam Al-Jehani, Julie Lamoureux, \\ Mohammad Maleki, Judith Marcoux
}

\begin{abstract}
Background: Intracranial hypertension can cause secondary damage after a traumatic brain injury. Aggressive medical management might not be sufficient to alleviate the increasing intracranial pressure (ICP), and decompressive craniectomy (DC) can be considered. Decompressive craniectomy can be divided into categories, according to the timing and rationale for performing the procedure: primary (done at the time of mass lesion evacuation) and secondary craniectomy (done to treat refractory ICP). Most studies analyze primary and secondary DC together. Our hypothesis is that these two groups are distinct and the aim of this retrospective study is to evaluate the differences in order to better predict outcome after DC. Methods: Seventy patients had DC over a period of four years at our center. They were divided into two groups based on the timing of the DC. Primary DC (44 patients) was done within 24 hours of the injury for mass lesion evacuation. Secondary DC (26 patients) was done after 24 hours and purely for the treatment of refractory ICP. Pre-op characteristics and post-op outcomes were compared between the two groups. Results: There was a significant difference in the mechanism of injury, the pupil abnormalities and Marshall grade between primary and secondary DC. There was also a significant difference in outcome with primary DC showing $45.5 \%$ good outcome and $40.9 \%$ mortality and secondary DC showing $73.1 \%$ good outcome and $15.4 \%$ mortality. Conclusions: Primary and secondary DC have different indications and patients characteristics. Outcome prediction following DC should be adjusted according to the surgical indication.
\end{abstract}

RÉSUMÉ: Craniectomie décompressive primaire ou secondaire : des indications et des résultats différents. Contexte : L'hypertension inracrânienne peut causer des dommages secondaires après un traumatisme crânien. Il se peut qu'un traitement médical agressif ne soit pas suffisant pour diminuer la pression intracrânienne (PIC) qui augmente et une craniectomie de décompression (CD) est alors envisagée. La CD peut être divisée en deux catégories selon le moment et la raison pour laquelle l'intervention est faite : primaire (effectuée au moment de l'évacuation de la lésion à effet de masse) et secondaire (effectuée pour traiter une PIC réfractaire). La plupart des études ont analysé ensemble la CD primaire et la CD secondaire. Nous avons émis l'hypothèse que ces deux groupes de patients sont différents et le but de cette étude rétrospective était d'évaluer leurs différences afin de mieux prédire le résultat après une CD. Méthode : Soixante-dix patients ont subi une CD au cours d'une période de quatre ans dans notre centre. Ils ont été divisés en deux groupes selon le moment où la $\mathrm{CD}$ a été effectuée. La CD primaire a été faite dans les 24 heures suivant l'accident pour évacuer une lésion à effet de masse chez 44 patients. Vingt-six patients ont subi une CD secondaire au delà des 24 premières heures pour traiter une PIC réfractaire. Nous avons comparé les caractéristiques préopératoires et l'issue postopératoire de ces deux groupes de patients. Résultats : Nous avons observé des différences significatives quant au mécanisme ayant provoqué la lésion, aux anomalies pupillaires et au score de Marshall entre la CD primaire et la CD secondaire ainsi qu'une différence significative quant au résultat : 45,5\% des patients ayant subi une CD primaire ont eu un bon résultat et la mortalité chez ces patients a été de 40,9\%, alors que dans le groupe de patients qui ont subi une CD secondaire 73,1\% ont eu un bon résultat avec 15,4\% de mortalité. Conclusions : Les indications de la CD primaire et de la CD secondaire ainsi que les caractéristiques des patients sont différentes. La prédiction du résultat de la $\mathrm{CD}$ devrait tenir compte de l'indication chirurgicale.

Can. J. Neurol. Sci. 2011; 38: 612-620

Intracranial hypertension is a well-known factor that could lead to unfavorable outcomes in traumatic brain injury (TBI) $\cdot^{1-4}$ Brain edema and high intracranial pressure (ICP) can often be controlled with medical therapy. Nevertheless, this might be insufficient and some patients gradually deteriorate in spite of maximal medical treatment. Hence, decompressive craniectomy (DC) could be considered. It provides a potentially good extracranial space for the edematous brain to expand into. This in turn would protect the vital brain structures from mass effect and improve cerebral autoregulation and cerebral blood flow. However, uncertainty remains regarding the efficacy and timing of DC, especially in the absence of an evacuable mass. ${ }^{5-11}$ Only one prospective randomized controlled trial has been completed to evaluate the efficacy of DC, and included pediatric patients

From the Department of Neurology and Neurosurgery, Montreal Neurological Hospital (AAJ, RSS, HAJ), Montreal General Hospital (JM, MM), McGill University Health Centre; Médicine sociale de préventive (JL), Université de Montréal, Montréal, QC,

Canada; Department of Neurosurgery (HAJ), King Fahad University Hospital,

Dammam University, Al-Khobar, Saudi Arabia.

Received December 6, 2010. Final Revisions Submitted March 8, 2011. Correspondence to: Judith Marcoux, Department of Neurology and Neurosurgery, Montreal General Hospital, McGill University Health Centre, 1650 Cedar Ave, Room L7-524, Montreal, Quebec, H3G 1A4, Canada. 
only. This study showed lower rate of death and unfavorable outcome when DC was used compared to maximal medical treatment, including barbiturate coma. ${ }^{12}$ Two ongoing randomized controlled trials including adult patients are currently under way, the Rescue ICP trial ${ }^{13}$ and the DECRA trial $^{14}$, aimed at determining whether DC improves outcome in severe TBI. They will include only patients with an ICP monitor and refractory intracranial hypertension.

Decompressive craniectomy can be divided into different categories, according to the timing and rationale for performing the procedure: primary (or prophylactic) craniectomy, when the craniectomy is done at the time of surgical decompression of a mass lesion, to prevent post-surgical increased ICP; ${ }^{15}$ and secondary (or therapeutic) craniectomy, when the craniectomy is done to treat ongoing refractory ICP. ${ }^{15-16}$ Most published studies that include both primary and secondary DC in TBI analyzed the two groups together, $, 11,17-28$ making comparison between patients characteristics and outcome difficult. In fact only one study analyzed outcomes separately. ${ }^{8}$

Our hypothesis is that these two groups of TBI patients with DC will have different pre-op characteristics and post-op outcomes. The aim of this retrospective study is to evaluate these differences in order to be able to better predict outcome after DC, according to the surgical indication.

\section{Methodology}

\section{Patient population and management}

Between September 1st, 2004 and August 31st, 2008, 1913 patients were admitted to the Montreal General Hospital-McGill University Health Centre (MGH-MUHC), a level 1 supraregional trauma center, with a diagnosis of TBI. Of the admitted patients, 1339 had a mild TBI (Glasgow Coma Scale (GCS) score of 13 to 15), 181 had a moderate TBI (GCS 9 to 12), and 393 had a severe TBI (GCS 3 to 8). ${ }^{29}$ All patients with a moderate or severe TBI, or mild with an abnormal computerized tomography (CT)-scan were initially evaluated by a dedicated trauma team, and subsequently by the neurosurgery service. Patients requiring immediate surgery were directed to the operating room. These patients had their ICP monitor inserted in the operating room. All the other patients were admitted to the intensive care unit. All patients with a GCS of 8 or less and an abnormal scan had an intracranial pressure monitor placed, according to the Brain Trauma Foundation guidelines. ${ }^{30}$ Appropriate measures to lower the ICP once over $20 \mathrm{mmHg}$ were given as indicated, including sedation and analgesia, head of bed elevation, cerebrospinal fluid drainage, hyperosmolar therapy, and in many cases barbiturate coma to induce burst-suppression pattern on the EEG approximately every ten seconds (see Figure 1 for the treatment algorithm). All patients were followed by a specialized early rehabilitation team, who provided multidisciplinary services and assured timely and appropriate discharge planning.

\section{Surgical procedure}

A decompressive craniectomy was most often done unilaterally, on the side of the most significant mass effect lesion, both for the primary and the secondary group. All the patients in our series were wearing a rigid cervical collar for c-

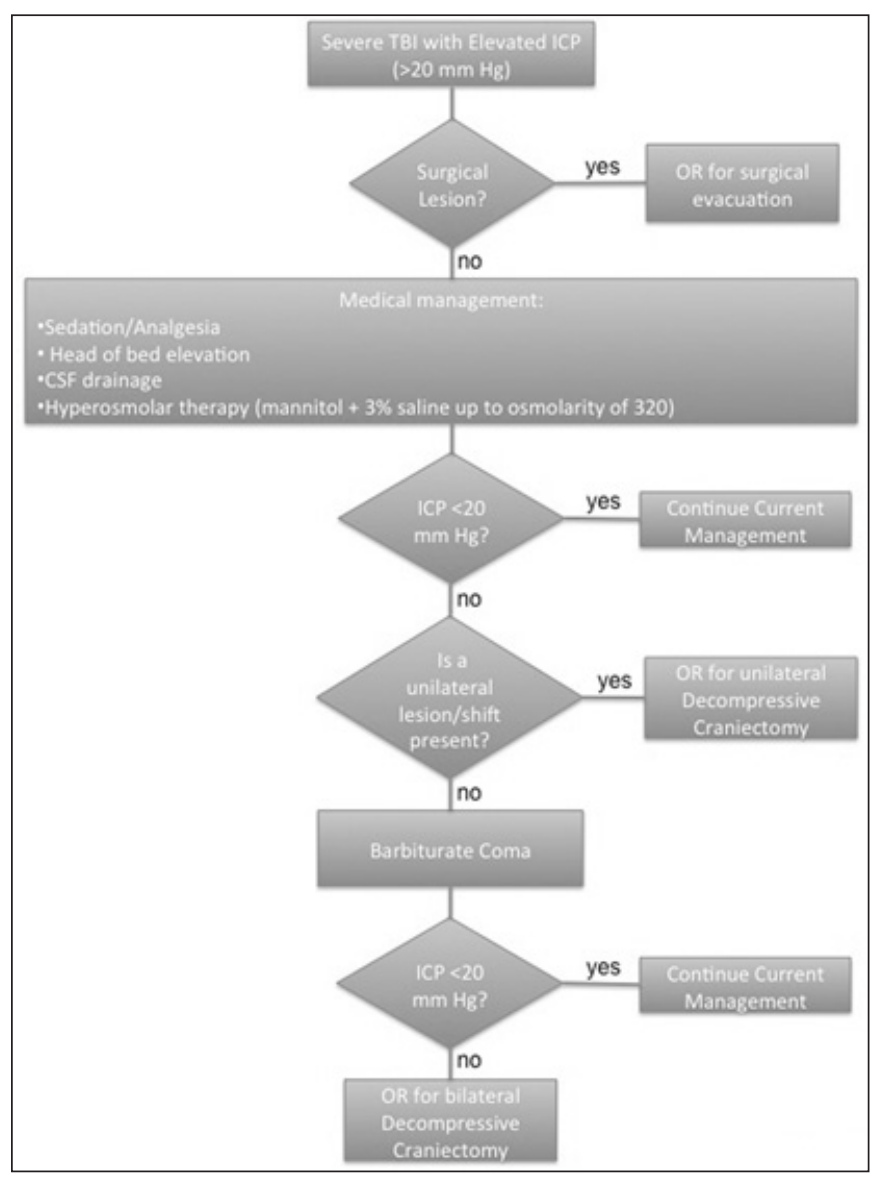

Figure 1: Intracranial hypertension treatment algorithm. TBI = traumatic brain injury, $O R=$ operating room, $C S F=$ cerebrospinal fluid, $I C P=$ intracranial pressure .

spine protection. Positioning therefore respected perfect alignment of the spine. We used a shoulder roll to obtain some rotation at the head. The incision would start at the hairline, two centimeters lateral to the midline and extended as posterior as possible in the parietal area, then extending inferiorly in the posterior temporal area and ending in front of the tragus. This would allow us to routinely have bone flaps measuring at least 14 by $10 \mathrm{~cm}$. The dura was opened in a stellate fashion and a large duraplasty was routinely performed, to allow for maximal expansion of the underlying brain. Secondary craniectomy was performed when maximal medical therapy failed to keep the intracranial pressure below $20 \mathrm{mmHg}$. This approach was standardized for all patients. On a few occasions, in the secondary craniectomy group, there was no clear unilateral pathology and no midline shift. In those cases, bilateral craniectomies were performed. We performed a craniectomy on one side that would go somewhat less posterior, to allow for positioning of the head on the other side for the second procedure. Then, we would reposition the patient on the other side and perform the same craniectomy on the opposite side. These patients therefore had two bone flaps removed. One patient had a bi-frontal craniectomy done. The bone flaps were kept in a $-80^{\circ} \mathrm{C}$ freezer until the cranioplasty could be performed. 
Table 1: Marshall CT Classification for Head Injury ${ }^{32}$

\begin{tabular}{|c|c|}
\hline Category & Definition \\
\hline Diffuse Injury I & no visible intracranial pathology seen on $\mathrm{CT}$ \\
\hline Diffuse Injury II & $\begin{array}{l}\text { cisterns are present with midline shift } 0-5 \mathrm{~mm} \text { and/or lesion densities present no high- or mixed-density } \\
\text { lesion }>25 \mathrm{~mL} \text {; may include bone fragments and foreign bodies }\end{array}$ \\
\hline Diffuse Injury III & cisterns compressed or absent with midline shift $0-5 \mathrm{~mm}$, no high- or mixed-density lesion $>25 \mathrm{~mL}$ \\
\hline Diffuse Injury IV & midline shift $>5 \mathrm{~mm}$, no high- or mixed-density lesion $>25 \mathrm{~mL}$ \\
\hline $\begin{array}{l}\text { Diffuse Injury V } \\
\text { (Evacuated Mass Lesion) }\end{array}$ & any lesion surgically evacuated \\
\hline $\begin{array}{l}\text { Diffuse Injury VI } \\
\text { (Non- Evacuated Mass } \\
\text { Lesion) }\end{array}$ & high- or mixed-density lesion $>25 \mathrm{~mL}$, not surgically evacuated \\
\hline
\end{tabular}

The cranioplasty was usually performed six to ten weeks after the initial trauma, if the patient's condition permitted undertaking the procedure.

\section{Data collection}

During this period, all patients who underwent a decompressive craniectomy for the treatment of their TBI were included in this study. They were identified through the Trauma Registry Database and the TBI Program Database. Their charts and CT scans were reviewed to assess for age, gender, mechanism of injury, GCS score after resuscitation, Injury Severity score (ISS), ${ }^{31}$ radiological findings with Marshall CT

Table 2: Glasgow outcome scale scores definition ${ }^{34}$

\begin{tabular}{l|l} 
GOS & \multicolumn{1}{c}{ Definition } \\
5 & $\begin{array}{l}\text { Good recovery: able to return to work or school } \\
4\end{array}$ \\
3 & $\begin{array}{l}\text { Moderate disability: able to live independently; unable to return } \\
\text { to work or school } \\
\text { independently }\end{array}$ \\
2 & $\begin{array}{l}\text { Persistent vegetative state: unable to interact with environment; } \\
\text { unresponsive }\end{array}$ \\
1 & Dead able to follow command/unable to live
\end{tabular}

grades (Table 1), ${ }^{32-33}$ ICP pre- and post-decompressive craniectomy, timing of surgery, indication for surgery, surgeryrelated complications, and Glasgow Outcome score (GOS) (Table 2). ${ }^{34-35}$ The GOS was given by the attending neurosurgeon at the time of outpatient clinic follow-up visit for the patients who went to rehabilitation or home. The timing of that follow-up was also recorded. For the patients transferred to a long-term care facility, the GOS was given according to a consensus within the multidisciplinary team at discharge from the acute care hospital. The MUHC Ethics Review Board and the Director of Professional Services approved this study; and the informed consent requirement was waived.

\section{Statistical analysis}

Patients were divided into primary, or early craniectomy (Group 1) and secondary, or late craniectomy (Group 2). Early craniectomy was done within 24 hours of injury and mainly for mass evacuation accompanied by secondary brain edema. Late craniectomy was done at least 24 hours after the injury and purely for uncontrolled ICP, once maximal medical therapy had failed to normalize ICP. A normal ICP was defined as $\leq$ $20 \mathrm{mmHg}$. Patient characteristics and CT findings between the two groups were compared using chi-square tests for nominal variables, t-tests for numerical variables and Mann-Whitney tests for ordinal variables. Pre- and post-operative ICP values were compared using paired t-tests. The association between baseline characteristics and the outcomes in each group was assessed using odds ratio as well as a $95 \%$ confidence interval around those odds ratio.

\section{RESULTS}

\section{Patients characteristics}

Seventy patients had a decompressive craniectomy. Their characteristics are detailed in Table 3 , and also divided according 
Table 3: Patients characteristics according to the timing of decompressive craniectomy

\begin{tabular}{|c|c|c|c|}
\hline & Total & $\begin{array}{c}\text { Primary } \\
\text { group }\end{array}$ & $\begin{array}{l}\text { Secondary } \\
\text { group }\end{array}$ \\
\hline Number & 70 & 44 & 26 \\
\hline Age & & & \\
\hline Mean $\pm \mathrm{SD}$ & $40 \pm 18.1$ & $46.3 \pm 18.5$ & $29.3 \pm 11.3$ \\
\hline Range & $16-83$ & 16-83 & $18-60$ \\
\hline Gender & & & \\
\hline Male & $60(85.7 \%)$ & $38(86.4 \%)$ & $22(84.6 \%)$ \\
\hline Female & $10(14.3 \%)$ & $6(13.6 \%)$ & $4(15.4 \%)$ \\
\hline Mechanism of $i$ & & & \\
\hline MVA & $34(48.5 \%)$ & $14(31.8 \%)$ & $20(76.9 \%)$ \\
\hline Fall & $20(28.6 \%)$ & $17(38.6 \%)$ & $3(11.5 \%)$ \\
\hline Gunshot & $6(8.6 \%)$ & $4(9.1 \%)$ & $2(7.7 \%)$ \\
\hline Assault & $5(7.1 \%)$ & $4(9.1 \%)$ & $1(3.8 \%)$ \\
\hline Bike & $3(4.3 \%)$ & $3(6.8 \%)$ & 0 \\
\hline Other & $2(2.9 \%)$ & $2(4.5 \%)$ & 0 \\
\hline GCS & & & \\
\hline Mean $\pm \mathrm{SD}$ & $7.6 \pm 3.4$ & $7.7 \pm 3.6$ & $7.3 \pm 2.9$ \\
\hline Range & 3-15 & $3-15$ & 4-14 \\
\hline ISS & & & \\
\hline Mean $\pm \mathrm{SD}$ & $33.7 \pm 10.2$ & $32.8 \pm 8.3$ & $35.4 \pm 12.8$ \\
\hline Range & $16-66$ & $16-50$ & $17-66$ \\
\hline Marshall Grade & & & \\
\hline M1 & 0 & 0 & 0 \\
\hline M2 & 5 & 4 & 1 \\
\hline M3 & 26 & 4 & 22 \\
\hline M4 & 1 & 1 & 0 \\
\hline M5 & 37 & 34 & 3 \\
\hline
\end{tabular}

$\mathrm{SD}=$ standard deviation; $\mathrm{MVA}=$ motor vehicle accident GCS = Glasgow Coma Scale score; ISS = Injury severity score. One patient in the early craniectomy group has no Marshall Grade, since no pre-op image was available

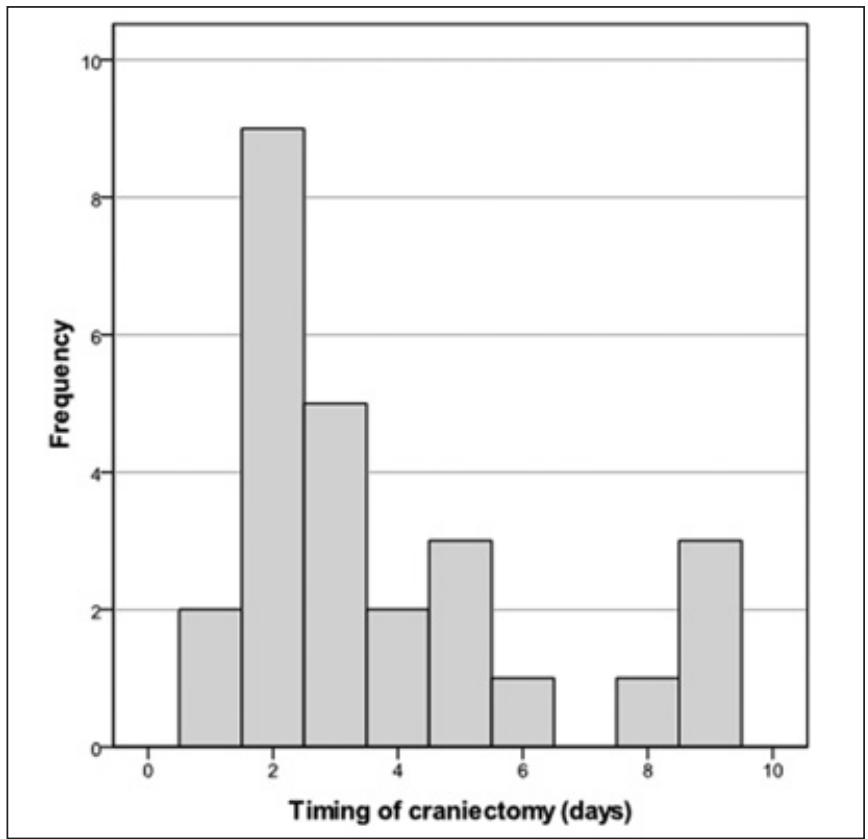

Figure 2: Number of patients who had late decompressive craniectomy done according to the number of days post-injury.
Table 4: Indications for primary craniectomy

\begin{tabular}{|l|c|}
\hline Condition & Number \\
\hline EDH & 33 \\
ICH & 4 \\
PHI & 2 \\
Brain swelling & 6 \\
\hline
\end{tabular}

$\mathrm{SDH}=$ Subdural hematoma; $\mathrm{EDH}=$ epidural hematoma; $\mathrm{ICH}=$ intracerebral hematoma; $\mathrm{PHI}=$ penetrating head injury

to the timing of the surgery. Eighty-six percent of the patients in this group were male, and similar between the two groups $\left(\chi_{1 \mathrm{df}}^{2}\right.$ $=0.041, p=0.840)$. In the late decompression group, there was a significantly higher percentage of MVA (76.9\% vs $31.8 \%$ ) compared to the early group whereas the early decompression group had a higher percentage of falls (38.6\% vs $11.5 \%)$ compared to the late group $\left(\chi_{5 \mathrm{df}}^{2}=14.667, \mathrm{p}=0.012\right)$. The secondary DC group was significantly younger $(29.7 \pm 11.3$ years old versus $46.30 \pm 18.5$ years old) than the primary DC group (t67.9df $=4.775, \mathrm{p}<0.001$ ). The median GCS score was 7.0, varying between 3 and 15 . The mean ( \pm standard deviation) of the ISS score was $33.7 \pm 10.2$. The initial GCS was not statistically different between the two groups $\left(\mathrm{Z}_{\text {Mann-Whitney }}=\right.$ $0.673, \mathrm{p}=0.501)$ and neither was the ISS score $\left(\mathrm{t} 3_{7.6 \mathrm{df}}=0.933\right.$, $\mathrm{p}=0.357$ ). Significantly more subjects had one or two dilated pupil(s) in the primary DC group compared to the secondary DC (37.2\% and $4.0 \%$ respectively, $\left.\chi_{1 \mathrm{df}}^{2}=9.299, \mathrm{p}=0.002\right)$. The distribution of the Marshall categories in the two groups was significantly different: while $79.1 \%$ of the primary DC group was classified in the "evacuated mass category", $84.6 \%$ of the secondary DC group was classified as a Marshall grade III (M3) $\left(\chi_{3 \mathrm{df}}^{2}=39.440, \mathrm{p}<0.001\right)$. The incidence of abnormal coagulation profile within the first 24 hours after the surgery was $57 \%$ in the primary DC group, while none of the patients in the secondary DC group had abnormal coagulation after their surgery.

\section{Indications for decompressive craniectomy}

The most common indication for primary decompressive craniectomy was an acute subdural bleeding (33 patients or $75 \%$ ). Three of these patients also had a second pathology (epidural hematoma, intracerebral hematoma and gunshot wound). Other indications were due to acute epidural bleeding, gunshot wounds, depressed skull fracture and severe cerebral swelling (Table 4). The only indication for a secondary craniectomy was an ICP not controlled by maximal medical therapy. 


\section{Timing of decompressive craniectomy}

In this sample, forty-four patients (62.9\%) underwent an early craniectomy, done within 24 hours of the trauma. Twenty-six patients $(37.1 \%)$ had a late decompressive craniectomy, done for ICP control without a mass lesion. The timing for a late craniectomy was on average 3.8 days $(\mathrm{SD}= \pm 2.5$ days) after the injury with a range of one to nine days. Forty-two percent (11 out of 26) of the late craniectomies were performed in the first two days post-trauma (Figure 2) and 84\% (22 out of 26) were done during the first week after trauma.

\section{Pre- and post-operative ICP difference}

The ICP was recorded immediately pre-operatively and immediately post-operatively in the secondary craniectomy group in 23 patients. Two patients did not have immediate preop ICP measures. The same two patients did not have post-op ICP monitoring device and the immediate ICP measure was not recorded in one patient. The mean pre-operative ICP was $33.5 \pm$ $12.3 \mathrm{mmHg}$ (range $20-72 \mathrm{mmHg}$ ) and the mean post-operative ICP was $9.1 \pm 4.6 \mathrm{mmHg}$ (range $3-20 \mathrm{mmHg}$ ). The postoperative ICP was significantly lower by an average of $24.8 \mathrm{~mm}$ $\mathrm{Hg}\left(\mathrm{t}_{22 \mathrm{df}}=8.33, \mathrm{p}<0.001\right)$ than the pre-operative ICP.

Because of the urgency for surgical intervention, most patients of the primary craniectomy group who had high ICP did not have an ICP monitor inserted prior to surgery. However, the ICP was recorded in six patients in both pre and post-operatively. The decline (from an average of $31.1 \pm 6.0 \mathrm{~mm} \mathrm{Hg}$ in predecompression to $14.5 \pm 11.6 \mathrm{~mm} \mathrm{Hg}$ in post-decompression) was also statistically significant $\left(\mathrm{z}_{\text {Wilcoxon rank }}=1.997, \mathrm{p}=0.046\right)$.

\section{Outcome measure}

The mean follow-up time after trauma for all patients discharged home or to a rehabilitation center was $10.7+/-9.8$ months $(11.6+/-10.6$ months for the early group and $8.3+/-6.4$ months for the late group). One patient in the primary DC group
Table 5: GOS score according to timing of craniectomy at follow-up

\begin{tabular}{c|c|c|}
\hline GOS & Primary group & Secondary group \\
\hline 1 & $18(40.9 \%)$ & $4(15.4 \%)$ \\
2 & 0 & $2(7.7 \%)$ \\
3 & $6(13.6 \%)$ & $1(3.8 \%)$ \\
4 & $9(20.5 \%)$ & $10(38.5 \%)$ \\
5 & $11(25 \%)$ & $9(34.6 \%)$ \\
\hline
\end{tabular}

GOS = Glasgow outcome scale

was discharged from the acute care hospital and returned back to his country of origin and consequently lost to follow-up. His GOS at discharge was 4 and the same score was kept for assessing late GOS. Two patients in the secondary DC group did not come to their follow-up appointment. Both of them also had a GOS of 4 at discharge from the hospital and the same score was kept for assessing late GOS. Glasgow Outcome Score at follow-up is detailed in Table 5. The mean GOS for the primary group was 2.89, while the mean GOS for the secondary group 3.69 , and this difference was statistically significant $\left(\mathrm{x}_{4 \mathrm{df}}^{2}=\right.$ $10.82, p=0.0286$.). A good outcome was achieved in $45.5 \%$ for the primary DC group and in $73.1 \%$ for the secondary DC group and this difference was also statistically significant $\left(\chi_{1 \mathrm{df}}^{2}=\right.$ $6.005, \mathrm{p}=0.014)$. The mortality rate (GOS of 1$)$ was significantly higher $(40.9 \%$ versus $15.4 \%)$ in the primary DC group compared to the secondary DC group $\left(\chi_{1 \mathrm{df}}^{2}=4.941, \mathrm{p}=0.026\right)$.

Table 6: Trauma and patient characteristics as determinants of outcome

\begin{tabular}{|c|c|c|c|c|}
\hline Determinant & $\begin{array}{c}\text { Primary DC } \\
\text { Odds of dying } \\
\text { (GOS 1) } \\
\end{array}$ & $\begin{array}{c}\text { Primary DC } \\
\text { Odds of poor outcome } \\
(\text { GOS }<4)\end{array}$ & $\begin{array}{l}\text { Secondary DC } \\
\text { Odds of dying } \\
\text { (GOS 1) }\end{array}$ & $\begin{array}{c}\text { Secondary DC } \\
\text { Odds of poor outcome } \\
(\text { GOS }<4) \\
\end{array}$ \\
\hline $\begin{array}{c}\text { Marshall grade } \geq 4 \\
\text { SDH }=\text { yes }\end{array}$ & $\begin{array}{c}\text { OR 9.72 } \\
(p=0.041) * \\
\text { OR } 10.62 \\
(p=0.032) *\end{array}$ & $\begin{array}{c}\text { OR } 7.50 \\
(p=0.025)^{*} \\
\text { OR } 14.06 \\
(p=0.003)^{*}\end{array}$ & $\begin{array}{c}\text { OR } 3.33 \\
(p=0.380) \\
-^{\mathrm{a}}\end{array}$ & $\begin{array}{c}\text { OR } 0.78 \\
(p=0.846) \\
-^{\mathrm{a}}\end{array}$ \\
\hline Age $\geq 40$ & $\begin{array}{c}\text { OR } 5.83 \\
(p=0.018) *\end{array}$ & $\begin{array}{c}\text { OR } 10.56 \\
(p=0.001)^{*}\end{array}$ & $\begin{array}{c}\text { OR } 1.13 \\
(p=0.921)\end{array}$ & $\begin{array}{c}\text { OR } 1.86 \\
(p=0.511)\end{array}$ \\
\hline Rebleed $=$ yes & $\begin{array}{c}\text { OR } 2.33 \\
(p=0.183)\end{array}$ & $\begin{array}{c}\text { OR } 1.11 \\
(p=0.865)\end{array}$ & $\begin{array}{l}\text { OR } 1.25 \\
(p=0.894)\end{array}$ & $\begin{array}{c}\text { OR } 1.67 \\
(p=0.729)\end{array}$ \\
\hline $\mathrm{GCS}<9$ & $\begin{array}{c}\text { OR } 1.91 \\
(p=0.328)\end{array}$ & $\begin{array}{c}\text { OR } 3.21 \\
(p=0.075)\end{array}$ & $\begin{array}{c}\text { OR } 2.35 \\
(p=0.589)\end{array}$ & $\begin{array}{c}\text { OR } 3.00 \\
(p=0.395)\end{array}$ \\
\hline Gender $=$ female & $\begin{array}{c}\text { OR } 1.53 \\
(p=0.628)\end{array}$ & $\begin{array}{c}\text { OR } 3.64 \\
(p=0.259)\end{array}$ & $\begin{array}{c}\text { OR } 0.56 \\
(p=0.719)\end{array}$ & $\begin{array}{c}\text { OR } 0.87 \\
(p=0.891)\end{array}$ \\
\hline
\end{tabular}

DC = decompressive craniectomy; SDH = presence of subdural hematoma; GCS = Glasgow Coma Scale score; GOS = Glasgow Outcome Scale score; OR = odds ratio. ${ }^{\text {a }}$ No subjects, * statistically significant. 
Table 7: Summary of studies published assessing the effect of DC on ICP from 1999 till present

\begin{tabular}{|c|c|c|}
\hline Study & Method & Outcomes \\
\hline Guerra $1999^{17}$ & $\begin{array}{l}57 \text { patients, primary }<24 \mathrm{~h}(17) \\
\text { secondary }>24 \mathrm{~h}(40)\end{array}$ & Pooled outcome analysis. Good outcome $58 \%$, PVS 9\%, Mortality $19 \%$ \\
\hline De Luca $2000^{41}$ & 22 patients all secondary DC & $41 \%$ good recovery, $18 \%$ severe disability, $23 \%$ PVS and $18 \%$ died \\
\hline Taylor $2001^{12}$ & 27 patients secondary bDC & ICP is lower post bDC ; reduced risk of death; reduced risk of PVS with bDC compared to MMM \\
\hline Coplin $2001^{42}$ & 29 patients, primary DC (12) vs craniotomy (17) & DC reduced mortality while yielding equivalent neurologic outcome for survivors \\
\hline Csokay $2002^{43}$ & 28 patients all secondary DC & Reduced mortality from $80-90 \%$ with MMM to $40 \%$ with DC \\
\hline Kontopoulos $2002^{44}$ & 9 patients, DC day 1 to 11 & Mortality rate $22 \%$, severe disability $11 \%$, good recovery $66 \%$ \\
\hline Albanèse $2003^{8}$ & $\begin{array}{l}40 \text { patients, primary }<24 \mathrm{~h}(27) \\
\text { secondary }>24 \mathrm{~h}(13)\end{array}$ & $\begin{array}{l}\text { Early DC: } 20 \% \text { good recovery, } 30 \% \text { PVS, } 50 \% \text { died } \\
\text { Secondary DC: } 38 \% \text { good recovery, } 38 \% \text { PVS, } 20 \% \text { died }\end{array}$ \\
\hline Meier $2003^{45}$ & $\begin{array}{l}80 \text { patients } \\
\text { Primary (53) vs secondary (27) }\end{array}$ & Pooled outcome analysis \\
\hline Faleiro $2005^{46}$ & 21 patients, all early DC & $52.5 \%$ had good outcome \\
\hline Kan $2006^{39}$ & $\begin{array}{l}51 \text { pediatric patients } \\
\text { Primary }(45) \text { vs secondary }(6)\end{array}$ & Mortality $=31.5 \%, 5 / 6$ patients with secondary DC died. \\
\hline Aarabi $2006^{9}$ & 50 patients secondary uDC & $85 \%$ ICP $<20 \mathrm{mmHg} ; 28 \%$ mortality; $40 \%$ good GOS; $14 \%$ PVS; $9 \%$ severe disability \\
\hline Skoglund $2006^{47}$ & 19 patients & $68 \%$ good outcome, $16 \%$ poor outcome, $11 \%$ mortality \\
\hline Chibbaro $2007^{10}$ & $\begin{array}{l}48 \text { patients, early }<18 \mathrm{~h}(28) \\
\text { secondary }>18 \mathrm{~h}(20)\end{array}$ & $\begin{array}{l}\text { Determinants of good outcome: early DC, younger age, higher preDC GCS; } 56 \% \text { good GOS with early } \\
\text { DC }\end{array}$ \\
\hline Jagannathan $2007^{48}$ & 23 patients & $30 \%$ mortality. Of survivors, $83 \%$ good outcome at 2 years, \\
\hline Olivecrona 2007 & 21 patients & $71 \%$ favorable outcome (vs $61 \%$ in non-DC controls), mortality $14 \%$ in both groups \\
\hline Howard $2008^{24}$ & $\begin{array}{l}40 \text { patients } \\
\text { Primary (16) vs secondary (24) }\end{array}$ & Pooled analysis. $55 \%$ mortality; $30 \%$ good outcome; $67 \%$ good outcome in survivors \\
\hline Faleiro $2008^{23}$ & $\begin{array}{l}89 \text { patients } \\
<6 \mathrm{~h}, 6-24 \mathrm{~h},>24 \mathrm{~h}\end{array}$ & $\begin{array}{l}\text { Outcome analysis pooled, mortality } 59 \% \text { if operated earlier and } 53 \% \text { if operated later. Admission GCS } \\
\text { was the prognostic determinant }\end{array}$ \\
\hline Ho $2008^{49}$ & 16 patients & $\begin{array}{l}\text { good control of ICP and improved brain tissue oxygenation; } 11 \text { poor outcome (GOS 1-3); } 5 \text { good outcome } \\
\text { (GOS 4-5), Mortality at } 6 \text { months } 37.5 \%\end{array}$ \\
\hline Timofeev $2008^{50}$ & 27 patients & $48 \%$ good outcome; $37 \%$ poor outcome; $15 \%$ mortality \\
\hline Figaji $2008^{51}$ & $\begin{array}{l}18 \text { pediatric patients } \\
\text { Primary }(8) \text { vs secondary }(10)\end{array}$ & Pooled analysis. $78 \%$ good outcome; $22 \%$ poor outcome; $5.6 \%$ mortality. \\
\hline Qiu $2009^{52}$ & $\begin{array}{l}74 \text { patients } \\
\text { All primary }\end{array}$ & $\begin{array}{l}\text { Comparison between large DC and temporoparietal DC favoring large DC. ( } 56.8 \% \text { good outcome vs } \\
32.4 \% \text {, and } 27 \% \text { mortality vs } 57 \% \text { ) }\end{array}$ \\
\hline Williams $2009^{28}$ & 171 patients & $56 \%$ good outcome; $32 \%$ mortality \\
\hline Daboussi $2009^{53}$ & 26 patients & Good outcome $42 \%$, PVS $27 \%, 31 \%$ mortality \\
\hline Bao $2010^{11}$ & $37 \%$ patients all bDC; $<48 \mathrm{~h}$ vs $3-7$ days & Pooled outcome analysis. $54.1 \%$ good outcome, $10.8 \%$ PVS, $18.9 \%$ mortality \\
\hline
\end{tabular}

Primary DC= from the onset of management; early DC $=$ within 24 hours $=$ secondary $\mathrm{DC}=$ after 24 hours; $\mathrm{uDC}=$ unilateral $\mathrm{DC}$; $\mathrm{bDC}=$ bilateral $\mathrm{DC}$; $\mathrm{MMM}=$ maximum medical management; $\mathrm{PVS}=$ persistent vegetative state

\section{Complications}

A patient from the late DC group suffered from cerebro-spinal fluid leak at the site of the craniectomy, requiring lumbar drainage for a few days. This patient made an excellent recovery with a GOS of 5. One patient from the early DC group who remained with a GOS of 2, later developed bone flap resorption.

The rate of intracranial hemorrhage progression was also assessed in both groups and divided into extra-axial and intraaxial, and mild (less than $1 \mathrm{~cm}^{3}$ increase) or major $\left(1 \mathrm{~cm}^{2}\right.$ increase or more). Twenty-four patients $(54.5 \%)$ in the primary craniectomy group re-bled postoperatively compared to two $(7.7 \%)$ in the secondary DC $\left(\chi_{1 \mathrm{df}}^{2}=15.367, \mathrm{p}<0.001\right)$. Nineteen $(79.1 \%)$ of those re-bleeds in the primary DC group were major (16 intra-axial and 4 extra-axial; one patient having both major intra-axial and extra-axial bleed) and 21 (95.5\%) were intra-axial (five mild, 16 major). Of those 24 patients in the early DC group, 12 died, 3 had a GOS of 3, 8 had a GOS of 4 and 1 had a GOS of 5 at follow-up. In the secondary DC group, one patient had a mild increase of his intracerebral contusion (GOS 2 at follow-up) and one patient had a major postoperative extra-axial bleed requiring a second emergency procedure. This patient also developed infection of the bone flap after it had been replaced. Despite this, the patient had a GOS of 4 at follow-up.

\section{Bilateral craniectomies}

Six patients had bilateral craniectomies done. One had an early craniectomy for an acute subdural hematoma. He developed severe intracranial hypertension 24 hours later and a second craniectomy on the opposite side for significant brain swelling was performed. Because of persistently poor neurological status, comfort measures were offered and he subsequently died. He was included as part of the primary craniectomy group. One patient had a bi-frontal decompressive craniectomy (late DC group) and he also died. The four others had late DC done on two sides and they all made an excellent recovery (GOS 5), including one patient who, while being draped in the operating room, had a cardio-circulatory arrest (electro-mechanical dissociation) due to the high ICP.

\section{Predictors of outcome}

We sought to determine which of the early characteristics of head trauma or demographic variables were associated with the outcome. We separated the groups to perform the analyses. Table 6 gives the odd ratios of having a poor outcome $(\mathrm{GOS}<4)$ or of dying (GOS 1) for the different determinants. In the secondary DC group, none of the early characteristics of head trauma (pupil dilatation, severity of trauma, mechanism of 
accident, occurrence of re-bleed, pre-op ICP, or Marshall classification) were associated with the GOS at discharge and last follow-up. None of the demographic data collected (age or gender) was associated with the GOS at dismissal either. However, in the primary DC group, the odds of death or poor outcome were significantly higher for those patients with a lower Marshall classification, an acute mass lesion subdural hematoma, or an age of 40 years or more. The rate of re-bleed, the location or the importance of the re-bleed, the severity of trauma, and the gender were not associated with the outcome in any of the groups.

\section{Discussion}

There is still much debate on when is the optimal timing for DC. There are no standardized protocols between different institutions. Our study shows that the timing of DC has to be adjusted according to the pathology being treated. Early or primary DC is dealing with surgical mass lesions while late or secondary DC is reserved for intracranial hypertension difficult to control by non-surgical means.

Our study also showed that patients requiring late DC differed from the early DC population with younger age, a high incidence of Marshall grade III CT-scan, a higher incidence of motor vehicle accidents (MVA) as trauma mechanism, less pupillary abnormalities, and no concurrent coagulopathy. The high incidence of MVA as a mechanism of trauma in the late DC group likely produced sudden decelerations, associated with diffuse axonal injuries and may explain why this particular group of patients developed over the course of a few days severe brain swelling and high ICP. The younger age, low incidence of papillary abnormalities, high incidence of Marshall grade III compared to grade $\mathrm{V}$, and the absence of concomitant coagulopathy all contributed to the better outcome achieved by the late DC group. The trigger for DC was an ICP consistently above $20 \mathrm{mmHg}$ despite maximal medical measures. This is a rather strict definition of uncontrollable ICP, and this relatively aggressive approach may also explain the high incidence of good outcome in our series of late DCs.

In our series, $45.5 \%$ survived after primary DC with favorable outcome. On the contrary, there was $40.9 \%$ mortality in this group which is actually an interesting finding. Almost all of the patients in the early DC group had a surgical mass lesion on CTscan (Marshall grade 5). It is our assumption that the high mortality rate most likely reflects the severity of the initial injury, combined with significant mass effect and early secondary injury. Indeed, many died in the early days following the trauma. The others died after they were offered comfort measures, based on their poor neurological recovery. The group of patients who survived likely had a less severe injury to the brain parenchyma, explaining their relatively good recovery.

Outcome in the early craniectomy group was significantly influenced by CT-scan findings, the presence of a surgical subdural hematoma, and older age; whereas in the late group patients were more homogeneous and none of these factors significantly correlated with outcome. This is at odds with what is currently in the literature regarding prognostic factors for severe TBI. We believe that the reasons for this discrepancy are that, first our late DC group is very homogenous in age, severity of injury, and pupillary findings; and second, the group is small. Therefore, no statistically significant factors could be found.

When looking at the reported outcome following DC, we have to be aware that, while some studies only report series of patients with intracranial hypertension unresponsive to conservative maneuvers (secondary DC), many include also patients who had early evacuation of mass lesion accompanied by DC (primary DC). Therefore, the rate of good outcome reported differs greatly ( $30 \%$ to $71.7 \%) .{ }^{8-11,24,26,36-38}$ Our study highlights the fact that the outcome significantly depends on the indication for DC. Table 7 summarizes the outcome of decompressive craniectomy studies. Most studies pooled the outcome results when including both primary and secondary craniectomy. However, three studies separated patients group according to the definition of primary and late craniectomy. The study from Albanèse et $\mathrm{al}^{8}$ confirms our findings where twice as many patients in the late craniectomy group achieved a good outcome (GOS 4 or 5), even if patients in that series had surgery only when they showed signs of herniation. In the study from Kan et $\mathrm{al}^{39}$, the mortality for secondary DC was higher. However, an important bias is that the indications for surgery were an ICP cutoff of $40 \mathrm{mmHg}$ and the presence of pupillary changes. It also included only pediatric patients. In the study by Chibbaro and Tacconi, ${ }^{10}$ an early DC correlated with a better outcome.

One major concern when performing DC is the risk of increasing intracranial hemorrhage because it may lead to further damage to the brain and even death. In fact, an increase in contusion size has been reported by a few studies. ${ }^{9-10,28,40}$ The results from this study again highlight the fact that this risk is mainly associated with early DC. This is likely due to the fact that traumatic lesions are still evolving, and that a subset of patients had coagulopathy due to their medication regiments or the acute traumatic injury. It is actually common to see increasing contusions, especially within the first 24 hours after the injury, even without any decompressive surgery. However, because of the relatively sudden decompression, DC may increase this risk. A late DC does not seem to carry the same risk at all with only one mild contusion increase in our series.

This study had limitations inherent to a retrospective review. In particular, only the GOS was used as an outcome measure. There was no more refined functional outcome or quality of life measures that could be used as these were not done systematically for all patients.

\section{Conclusion}

The reported outcome following DC has to be adjusted according to the indication for surgery. Early (or primary) and late (or secondary) DC groups differ by their age, CT-scan findings, mechanism of injury, pupillary abnormalities and coagulation abnormalities. The mortality rate for patients requiring an early craniectomy was significantly higher than in the late craniectomy group, as they had more severe injuries and required early and very aggressive intervention to try and save their lives. Post-operative complication rate was also higher. Other factors, including CT-scan findings, older age and the presence of a surgical subdural hematoma also affected the outcome. Patients in the secondary craniectomy group were 
more homogeneous, had less surgical complications, and achieved a significantly better outcome.

\section{ACKNOWLEDGMENTS}

The authors thank Mrs. Johanne Prud'homme from the Trauma Registry of the Montreal General Hospital for quickly providing the necessary data. We also thank Mrs. Mitra Feyz, Director of the Traumatic Brain Injury Program, for providing the data from the Traumatic Brain Injury data bank and for her continuous support.

\section{REFERENCES}

1. Marmarou A, Anderson RL, Ward JD, et al. Impact of ICP instability and hypotension on outcome in patients with severe head trauma. J Neurosurg. 1991;75:S59-6.

2. Young JS, Blow O, Turrentine F, Claridge JA, Schulman A. Is there an upper limit of intracranial pressure in patients with severe head injury if cerebral perfusion pressure is maintained? Neurosurg Focus. 2003;15:E2.

3. Balestreri M, Czosnyka M, Hutchinson $\mathrm{P}$, et al. Impact of intracranial pressure and cerebral perfusion pressure on severe disability and mortality after head injury. Neurocrit Care. 2006; 4:8-13.

4. Grinkeviciūte DE, Kevalas R, Matukevicius A, Ragaisis V, Tamasauskas A. Significance of intracranial pressure and cerebral perfusion pressure in severe pediatric traumatic brain injury. Medicina (Kaunas). 2008;44:119-25

5. Murr R, Stummer W, Schürer L, Polasek J. Cerebral lactate production in relation to intracranial pressure, cranial computed tomography findings, and outcome in patients with severe head injury. Acta Neurochir (Wien). 1996;138:928-36.

6. Kunze E, Meixensberger J, Janka M, Sörensen N, Roosen K. Decompressive craniectomy in patients with uncontrollable intracranial hypertension. Acta Neurochir Suppl. 1998;71:16-8.

7. Schneider GH, Bardt T, Lanksch WR, Unterberg A. Decompressive craniectomy following traumatic brain injury: ICP, CPP and neurological outcome. Acta Neurochir Suppl. 2002;81:77-9.

8. Albanèse J, Leone M, Alliez JR, et al. Decompressive craniectomy for severe traumatic brain injury: Evaluation of the effects at one year. Crit Care Med. 2003;31:2535-8.

9. Aarabi B, Hesdorffer DC, Ahn ES, Aresco C, Scalea TM, Eisenberg HM. Outcome following decompressive craniectomy for malignant swelling due to severe head injury. J Neurosurg. 2006; 104:469-79.

10. Chibbaro S, Tacconi L. Role of decompressive craniectomy in the management of severe head injury with refractory cerebral edema and intractable intracranial pressure. Our experience with 48 cases. Surg Neurol. 2007;68:632-8.

11. Bao YH, Liang YM, Gao GY, Pan YH, Luo QZ, Jiang JY. Bilateral decompressive craniectomy for patients with malignant diffuse brain swelling after severe traumatic brain injury: a 37-case study. J Neurotrauma. 2010;27:341-7.

12. Taylor A, Butt W, Rosenfeld J, et al. A randomized trial of very early decompressive craniectomy in children with traumatic brain injury and sustained intracranial hypertension. Childs Nerv Syst. 2001;17:154-62.

13. Hutchinson PJ, Corteen E, Czosnyka M, et al. Decompressive craniectomy in traumatic brain injury: the randomized multicenter RESCUEicp study (www.RESCUEicp.com). Acta Neurochir Suppl. 2006;96:17-20

14. Cooper DJ, Rosenfeld JV, Murray L, et al. Early decompressive craniectomy for patients with severe traumatic brain injury and refractory intracranial hypertension--a pilot randomized trial. J Crit Care. 2008;23:387-93.

15. Sahuquillo J. Decompressive craniectomy for the treatment of refractory high intracranial pressure in traumatic brain injury. Cochrane Database Syst Rev. 2009; Issue 4.
16. Guerra KW, Piek J, Gaab MR. Decompressive craniectomy to treat intracranial hypertension in head injury patients. Intensive Care Med. 1999a;25:1327-9.

17. Guerra WK, Gaab MR, Dietz H, Mueller JU, Piek J, Fritsch MJ. Surgical decompression for traumatic brain swelling: indications and results. J Neurosurg. 1999 Feb;90(2):187-96.

18. Münch E, Horn P, Schürer L, Piepgras A, Paul T, Schmiedek P. Management of severe traumatic brain injury by decompressive craniectomy. Neurosurgery. 2000;47:315-22.

19. Jiang JY, Xu W, Li WP, et al. Efficacy of standard trauma craniectomy for refractory intracranial hypertension with severe traumatic brain injury: a multicenter, prospective, randomized controlled study. J Neurotrauma. 2005;22:623-8.

20. Meier U, Gräwe A, König A. The importance of major extracranial injuries by the decompressive craniectomy in severe head injuries. Acta Neurochir Suppl. 2005;95:55-7.

21. Ucar T, Akyuz M, Kazan S, Tuncer R. Role of decompressive surgery in the management of severe head injuries: prognostic factors and patient selection. J Neurotrauma. 2005;2:1311-8.

22. Pompucci A, De Bonis P, Pettorini B, Petrella G, Di Chirico A, Anile C. Decompressive craniectomy for traumatic brain injury: patient age and outcome. J Neurotrauma. 2007;24:1182-8.

23. Faleiro RM, Faleiro LC, Caetano E, et al. Decompressive craniotomy: prognostic factors and complications in 89 patients. Arq Neuropsiquiatr. 2008;66:369-73.

24. Howard JL, Cipolle MD, Anderson M, et al. Outcome after decompressive craniectomy for the treatment of severe traumatic brain injury. J Trauma. 2008;65:380-5.

25. Morgalla MH, Will BE, Roser F, Tatagiba M. Do long-term results justify decompressive craniectomy after severe traumatic brain injury? J Neurosurgery. 2008;109:685-90.

26. Yang XF, Wen L, Shen F, et al. Surgical complications secondary to decompressive craniectomy in patients with a head injury: a series of 108 consecutive cases. Acta Neurochir (Wien). 2008; 150:1241-7.

27. Rubiano AM, Villarreal W, Hakim EJ, et al. Early decompressive craniectomy for neurotrauma: an institutional experience. Ulus Travma Acil Cerrahi Derg. 2009;15:28-38.

28. Williams RF, Magnotti LJ, Croce MA, et al. Impact of decompressive craniectomy on functional outcome after severe traumatic brain injury. J Trauma. 2009;66:1570-4.

29. Teasdale G, Jennett B. Assessment of coma and impaired consciousness: a practical scale. Lancet. 1974;13:81-4.

30. Bratton SL, Chestnut RM, Ghajar J, et al. Guidelines for the management of severe traumatic brain injury. VI. Indications for intracranial pressure monitoring. Brain Trauma Foundation; American Association of Neurological Surgeons; Congress of Neurological Surgeons; Joint Section on Neurotrauma and Critical Care. J Neurotrauma. 2007; 24:S37-44.

31. Baker SP, O'Neill B, Haddon W Jr, Long WB. The Injury Severity Score: a method for describing patients with multiple injuries and evaluating emergency care. J Trauma. 1974;14: 187-96.

32. Marshall LF, Eisenberg HM, Jane JA. A new classification of head injury based on computerized tomography. J. Neurosurg. 1991; 75:S14-20.

33. Marshall LF, Marshall SB, Klauber MR, et al. The diagnosis of head injury requires a classification based on computed axial tomography. J Neurotrauma. 1992;9:S287-92.

34. Jennett B, Bond M. (1975). Assessment of outcome after severe brain damage: a practical scale. Lancet. 1975;1:480-4.

35. Jennett B, Snoek J, Bond MR. Disability after severe head injury: observations on the use of the Glasgow Outcome Scale. J. Neurol Neurosurg Psychiatry. 1981;44:285-93.

36. Polin RS, Shaffrey ME, Bogaev CA, et al. Decompressive bifrontal craniectomy in the treatment of severe refractory posttraumatic cerebral edema. Neurosurgery. 1997;41:84-92.

37. Olivecrona M, Rodling-Wahlström M, Naredi S, Koskinen LO. Effective ICP reduction by decompressive craniectomy in patients with severe traumatic brain injury treated by an ICPtargeted therapy. J Neurotrauma. 2007;24:927-35.

38. Li G, Wen L, Yang XF, Zheng XJ, Zhan RY, Liu WG. Efficacy of large decompressive craniectomy in severe traumatic brain injury. Chin J Traumatol. 2008;11:253-6. 
39. Kan P, Amini A, Hansen K, et al. Outcomes after decompressive craniectomy for severe traumatic brain injury in children. J Neurosurg. 2006;105(Suppl):337-42.

40. Wagner S, Schnippering H, Aschoff A, Koziol JA, Schwab S, Steiner T. Suboptimum hemicraniectomy as a cause of additional cerebral lesions in patients with malignant infarction of the middle cerebral artery. J Neurosurg. 2002;94:693-6.

41. De Luca GP, Volpin L, Fornezza U, et al. The role of decompressive craniectomy in the treatment of uncontrollable post-traumatic intracranial hypertension. Acta Neurochir Suppl. 2000;76:401-4.

42. Coplin WM, Cullen NK, Policherla PN, et al. Safety and feasibility of craniectomy with duraplasty as the initial surgical intervention for severe traumatic brain injury. J Trauma. 2001;50:1050-9.

43. Csokay A, Pataki G, Nagy L, Belán K. Vascular tunnel construction in the treatment of severe brain swelling caused by trauma and $\mathrm{SAH}$. (evidence based on intra-operative blood flow measure). Neurol Res. 2002; 24:157-60.

44. Kontopoulos V, Foroglou N, Patsalas J, et al. Decompressive craniectomy for the management of patiens with refractory hypertension: should it be reconsidered? Acta Neurochir. 2002; 144:791-6.

45. Meier U, König A, Gräwe A. The importance of major extracranial injuries by the decompressive craniectomy in severe head injuries. Acta Neurochir Suppl. 2005;95:55-7.

46. Faleiro RM, Pimenta NJ, Faleiro LC, Cordeiro AF, Maciel CJ, Gusmão SN. [Decompressive craniotomy for the early treatment of traumatic intracranial hypertension.]. Arq Neuropsiquiatr. 2005;63:508-13
47. Skoglund TS, Eriksson-Ritzén C, Jensen C, Rydenhag B. Aspects on decompressive craniectomy in patients with traumatic head injuries. J Neurotrauma. 2006;23:1502-9.

48. Jagannathan J, Okonkwo DO, Dumont AS, et al. Outcome following decompressive craniectomy in children with severe traumatic brain injury: a 10-year single-center experience with long-term follow up. J Neurosurg. 2007;106(Suppl):268-75.

49. Ho CL, Wang CM, Lee KK, Ng I, Ang BT. Cerebral oxygenation, vascular reactivity, and neurochemistry following decompressive craniectomy for severe traumatic brain injury. J Neurosurg. 2008;108:943-9.

50. Timofeev I, Czosnyka M, Nortje J, et al. Effect of decompressive craniectomy on intracranial pressure and cerebrospinal compensation following traumatic brain injury. J Neurosurg. 2008; 108:66-73.

51. Figaji AA, Fieggen AG, Argent AC, Le Roux PD, Peter JC. Intracranial pressure and cerebral oxygenation changes after decompressive craniectomy in children with severe traumatic brain injury. Acta Neurochir Suppl. 2008;102:77-80.

52. Qiu W, Guo C, Shen H, et al. Effects of unilateral decompressive craniectomy on patients with unilateral acute post-traumatic brain swelling after severe traumatic brain injury. Crit Care. 2009; 13:R185.

53. Daboussi, A, Minville V, Leclerc-Foucras S, et al. Cerebral hemodynamic changes in severe head injury patients undergoing decompressive craniectomy. J Neurosurg Anesthesiol. 2009;21: $339-45$. 